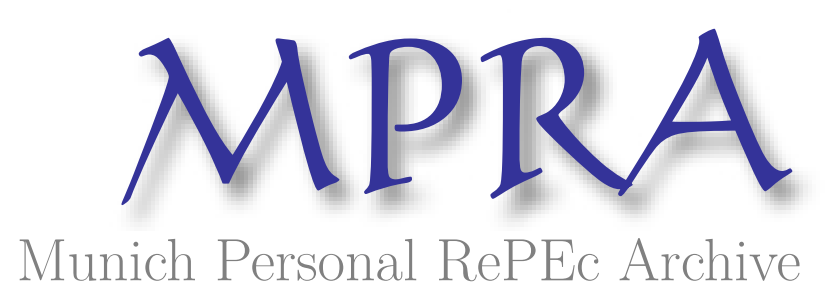

Risk Seekers May Be Antisocial After All

Da Silva, Sergio

Federal University of Santa Catarina

30 October 2014

Online at https://mpra.ub.uni-muenchen.de/60564/

MPRA Paper No. 60564, posted 12 Dec 2014 17:01 UTC 
Clinical and Experimental Medical Sciences, vol. 2, 2014, no. 3, 87 - 95

HIKARI Ltd, www.m-hikari.com

http://dx.doi.org/10.12988/cems.2014.489

\title{
Risk Seekers May Be Antisocial
}

\section{After All}

\section{Sergio Da Silva}

Graduate Program in Economics Federal University of Santa Catarina Florianopolis SC, 88049-970, Brazil

\author{
Raul Matsushita \\ Department of Statistics \\ University of Brasilia \\ Brasilia DF, 70910-900, Brazil
}

\section{Luiza Ugarte}

Graduate Program in Neuroscience

Federal University of Rio Grande Do Sul

Porto Alegre RS, 90046-900, Brazil

\section{Mateus De Carvalho}

Department of Economics

University of Birmingham

Birmingham, B15 2TT, United Kingdom

Copyright (C) 2014 Sergio Da Silva, Raul Matsushita, Luiza Ugarte and Mateus De Carvalho. This is an open access article distributed under the Creative Commons Attribution License, which permits unrestricted use, distribution, and reproduction in any medium, provided the original work is properly cited.

\begin{abstract}
Undergraduates were given a battery of psychological tests to gauge their degree of antisocial personality traits (psychopathy, Machiavellianism and nihilism). The students also responded to questionnaires to assess their attitudes toward risk and
\end{abstract}


intertemporal choice. Biological attributes of the respondents were also collected. We found a correlation between psychopathic, Machiavellian and nihilistic traits in the sample, and also that risk seekers were antisocial. Additionally, we found, on average, that younger subjects presented higher levels of psychopathy; atheists were more Machiavellian; and atheists who were anxious tend to be nihilists. Moreover, boys born from younger mothers were more risk seeking than girls born from older mothers. We also found older subjects to be less patient.

Keywords: Risk, Patience, Psychopathy, Machiavellianism, Nihilism, Biological attributes

\section{Introduction}

Bartels and Pizarro [1] gave 208 undergraduates a battery of tests and measured on a scale how utilitarian their responses were (see Appendix 1 available at http://dx.doi.org/10.6084/m9.figshare.1165563). The participants also responded to a series of statements intended to elicit their individual psychologies. The instructions were designed to measure psychopathy, Machiavellianism, and one's sense of how meaningful life is. They found a strong link between utilitarian answers and such personality traits. The three traits are examples of socially aversive personalities [8].

The finding that utilitarians are "antisocial" people prompted us to wonder about the status of risk seekers and the impatient. Are they antisocial, too? Our experiment, based on Bartels and Pizzaro's, suggests that risk seekers are possibly antisocial. And other important correlations were found between the individual psychologies, biological attributes, and the attitudes toward risk and intertemporal choice.

The next section describes the methods adopted in the experiment. Then, data are presented in Section 3 while Section 4 shows the findings. Section 5 contrasts such findings with the literature, and Section 6 concludes the study.

\section{Method Summary}

Google Docs questionnaires were sent online to 359 undergraduates from the Federal University of Santa Catarina and the University of Brasilia, both in Brazil. The participants were asked to respond to five types of questionnaires. The questionnaires involved a 26-item psychopathy scale based on Levenson et al. [10], the 20-item Machiavellianism scale of Christie and Geis [2] and the 18-item no-meaning scale of Kunzendorf et al. [9]. The questionnaires relative to risk and intertemporal choice were taken from Frederick [7]. The 18-item questionnaire of risk involved three subsets of choices: (1) certain gains versus higher expected value gambles, (2) certain gains versus lower expected value gambles, and (3) 
certain losses versus lower expected value gambles. The eight-item questionnaire of intertemporal choice involved hypothetical choices between an immediate reward and a larger delayed reward (see Appendices 2-6 available at http://dx.doi.org/10.6084/m9.figshare.1165563). In the end, the points for each participant were added to measure his or her total score regarding each trait.

We also applied a pre-survey questionnaire to gather information about participant's gender, age, and mother's age, whether they were right-handed or left-handed, whether they had children, and whether they were religious or atheist. We also presented them with a continuous "affect scale," ranging from "very anxious" and "moderately anxious" to "emotionless," "moderately excited" and "very excited." Such information assesses the "biological" attributes of the participants [4].

\section{Data}

Of the 359 respondents, one failed to answer the pre-survey on the biological attributes. Of the remaining 358 respondents, 191 were female. There were 245 respondents under the age of 25 . The combined number of left-handed participants (27) and ambidextrous participants made up 10 percent of the sample. Respondents who were born from young mothers (those under 25) made up 29 percent of the sample. Forty-two of the respondents were parents. Sixty-one percent of the sample of college students reported to believe in God. As for the emotional state of the participants, 34 described themselves as "very anxious;" 149 reported to be "moderately anxious;" 73 feel "emotionless;" 88 were "moderately excited;" and 14 were "very excited."

\section{Results}

Apart from the variable nihilism, the distributions of total scores of the other psychological and economic variables seemed to be normally distributed at first glance (Figure 1). But, they failed a Kolmogorov-Smirnov test of Gaussianity. We then considered Box-Cox power transformations performed on the original variables in order to get approximate normal residuals. As a result, for the variables psychopathy (with power 0.5) and Machiavellianism (with power 0.7), we found the null hypothesis of normally distributed residuals not to be rejected at the 5 percent significance level. However, for the variable nihilism, the null of normally distributed residuals was rejected with a $p$-value of less than 1 percent. The distribution of the total scores of psychopathy was slightly positively skewed (Figure 1), thus suggesting on one hand that most participants showed low psychopathy levels, but, on the other hand, that a few participants showed high levels of this psychological trait. The distribution of the total scores of Machiavellianism showed a cluster around the scores ranged from 45 to 75 , and a low frequency at extreme scores $(35,40,80$ and 85$)$. The distribution of the 
variable nihilism showed only a very few participants with a high level of the trait, suggesting that most respondents viewed life as purposeful. As for the distributions of the economic variables (risk and patience), risk (when gains were involved) presented less variance than patience.

Table 1 shows Pearson correlation coefficients for the psychological and economic variables. Psychopathy, Machiavellianism and nihilism were correlated. Participants showing higher scores on the psychopathy test also scored higher in the Machiavellianism and nihilism tests. Table 1 also shows a linear positive correlation between risk (when gains were involved) and patience, meaning that less risk-averse participants also tended to be less impatient. As discussed in Section 5, this finding is in line with some studies, but contradicts others.

Also, there was a positive correlation between risk in the domain of gains and Machiavellianism, which was significant at the 10 percent level ( $p$-value $=$ 0.06). In the domain of losses, risk and psychopathy were significantly correlated at the 5 percent level $(p$-value $=0.044)$. Taken together, these findings suggest a correlation between risk and both psychopathy and Machiavellianism.

By adopting the best subset regression method, we also found correlations between some biological attributes of the participants and the psychological and economic variables. For each target variable, we considered the influence of all potential combinations of co-variables using Akaike information criterion. The goal was to sort the best candidate models, therefore a diagnostic analysis of the models was conducted in order to select the most appropriate one. Although we have found low $R$ squared for the models (which means low predictive ability from the standpoint of one individual), the statistical significance of the regression coefficients revealed the presence of group associations.

Beyond the expected relation between psychopathy, Machiavellianism, and nihilism, Table 2 shows the younger subjects in the sample to present higher levels of psychopathy on average. Table 3 shows atheists scored higher on the Machiavellianism test. Table 4 suggests atheists who were anxious tended to be nihilists. Table 5 shows boys born from younger mothers were more risk seekers for gains than girls born from older mothers. And Table 6 shows older subjects tended to be less patient. Additionally, in line with the correlations shown in Table 1, the regression model conjointly revealed a positive association between risk for gains and impatience and, at the same time, a negative association between risk for losses and impatience. When both factors were considered together, those who were both less risk averse for gains and more risk averse for losses also tended to be less impatient. Finally, Table 7 indicates being less patient was related to average risk seeking when losses were involved. This implies those who were risk averse for losses were more patient. Such results were further validated by diagnostic checking (see Appendix 7 available at http://dx.doi.org/10.6084/m9.figshare.1165563). 

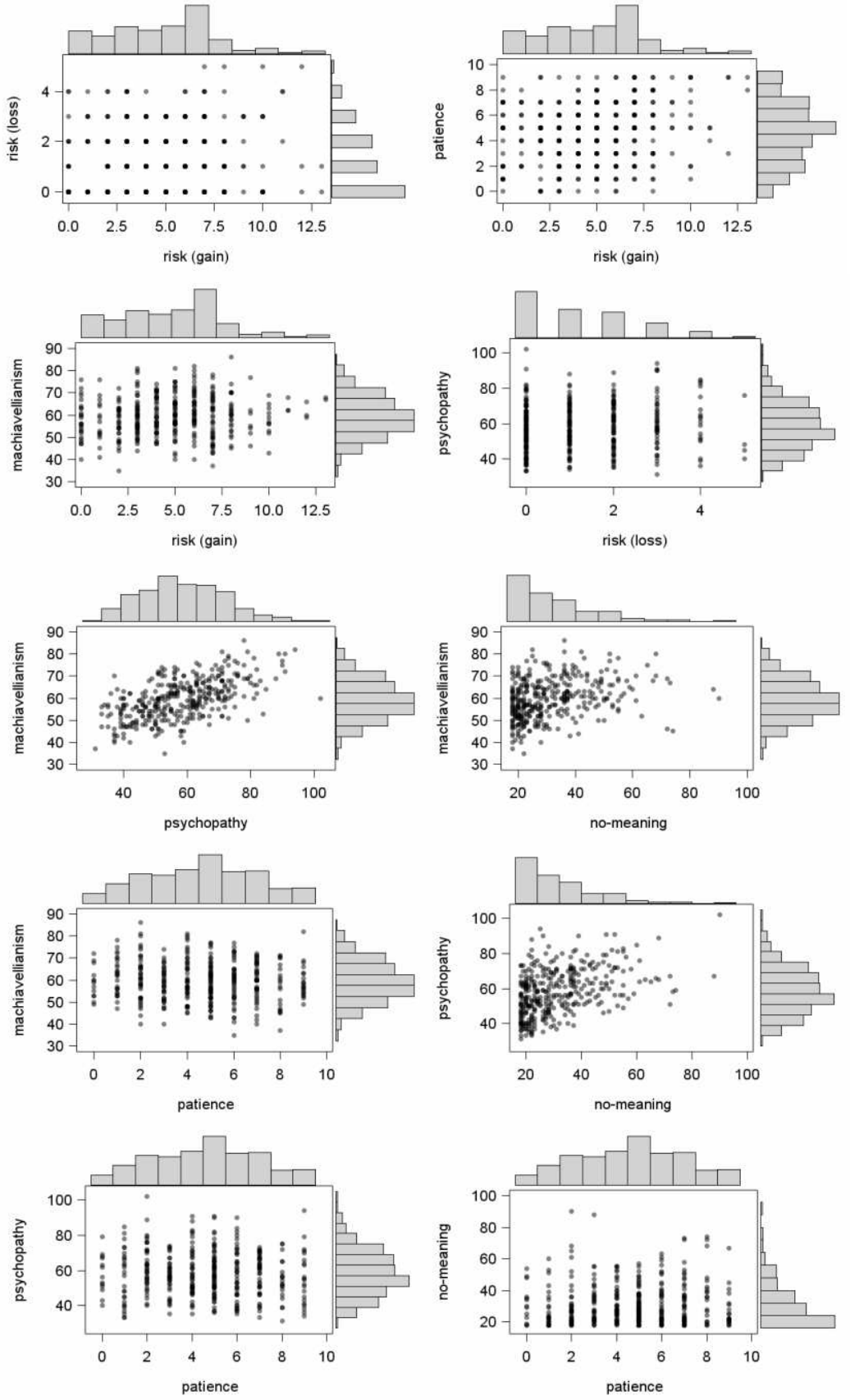

Figure 1. Scatter plots and marginal histograms of the total scores of the psychological and economic variables 
Table 1. Correlations between the economic and psychological variables

\begin{tabular}{llllll}
\hline & Risk (gains) & Risk (losses) & Patience & Psychopathy & Machiavellianism \\
Risk (losses) & 0.10 & & & \\
Patience & $(.066)$ & & & \\
& $\mathbf{0 . 2 1}$ & -0.08 & & \\
Psychopathy & $(<.0001)$ & $(.106)$ & & \\
& 0.06 & $\mathbf{0 . 1 1}$ & -0.06 & & \\
Machiavellianism & $(0.222)$ & $\mathbf{( 0 . 0 4 4 )}$ & $(0.285)$ & & \\
& 0.10 & 0.009 & -0.08 & $\mathbf{0 . 5 7}$ & \\
No meaning & $(0.059)$ & $(0.863)$ & $(0.133)$ & $\mathbf{( < . 0 0 0 1 )}$ & \\
& 0.03 & 0.026 & 0.04 & $\mathbf{0 . 4 2}$ & $\mathbf{0 . 3 0}$ \\
& $(0.603)$ & $(0.622)$ & $(0.442)$ & $\mathbf{( < . 0 0 0 1 )}$ & $\mathbf{( < . 0 0 0 1 )}$ \\
\hline
\end{tabular}

Note: $p$-values in parentheses

Table 2. Psychopathy ${ }^{0.5}$ regressed against nihilism, Machiavellianism ${ }^{0.7}$ and age

\begin{tabular}{lclcl}
\hline Variable & Estimate & Std Error & $t$ stat & Pr $>|t|$ \\
\hline Intercept & 4.76 & 0.602 & 7.91 & $<0.0001$ \\
Nihilism $^{*}$ & 0.02 & 0.003 & 5.85 & $<0.0001$ \\
Machiavellianism $^{0.7}$ & 0.22 & 0.020 & 10.77 & $<0.0001$ \\
Age & -0.48 & 0.134 & -3.59 & 0.0004 \\
\hline
\end{tabular}

Note: Psychopathy ${ }^{0.5}$ and Machiavellianism ${ }^{0.7}$ are Box-Cox power transformations run on the original variables in order to get approximate normal residuals. The null hypothesis of normally distributed residuals was not rejected at the 5 percent significance level (using the Kolmogorov-Smirnov test). The variable age was taken in logs.

Table 3. Machiavellianism ${ }^{0.7}$ regressed against psychopathy ${ }^{0.5}$ and religiousness

\begin{tabular}{lclll}
\hline Variable & Estimate & Std Error & $t$ stat & Pr $>|t|$ \\
\hline Intercept & 8.70 & 0.756 & 11.51 & $<0.0001$ \\
Psychopathy & 0.5 & 0.095 & 12.45 & $<0.0001$ \\
Religiousness & 1.19 & 0.167 & -2.60 & 0.0097 \\
\hline
\end{tabular}

Table 4. Nihilism regressed against psychopathy ${ }^{0.5}$, religiousness and excitement

\begin{tabular}{lcccc}
\hline Variable & Estimate & Std Error & $t$ stat & $\operatorname{Pr}>|t|$ \\
\hline Psychopathy & 0.5 & 0.133 & 36.36 & $<0.0001$ \\
Religiousness & 4.83 & 1.200 & -5.12 & $<0.0001$ \\
Excitement & -6.15 & 1.329 & -3.72 & 0.0002 \\
\hline
\end{tabular}

Note: The variable excitement equals one if a participant was very or moderately excited, but otherwise equals zero.

Table 5. Risk (gains) regressed against patience, gender and mother's age

\begin{tabular}{lcccc}
\hline Variable & Estimate & Std Error & t stat & Pr $>|t|$ \\
\hline Intercept & 4.57 & 0.855 & 5.35 & $<0.0001$ \\
Patience & 0.24 & 0.059 & 4.13 & $<0.0001$ \\
Gender & 1.30 & 0.277 & 4.49 & $<0.0001$ \\
Mother's age & -0.03 & 0.014 & -2.13 & 0.0341 \\
\hline
\end{tabular}

Note: The variable gender equals one if a participant was male and equals zero if female. 
Table 6. Patience regressed against risk (gains), risk (losses), Machiavellianism ${ }^{0.7}$ and age

\begin{tabular}{lclcc}
\hline Variable & Estimate & Std Error & $t$ stat & $P r>|t|$ \\
\hline Intercept & 7.45 & 1.324 & 5.63 & $<.0001$ \\
Risk (gains) & 0.19 & 0.046 & 4.25 & $<.0001$ \\
Risk (losses) & -0.22 & 0.010 & -2.32 & 0.0212 \\
Machiavellianism $^{0.7}$ & -0.15 & 0.069 & -2.28 & 0.0233 \\
Age & -0.03 & 0.014 & -2.14 & 0.0333 \\
\hline \multicolumn{7}{l}{} \\
Table 7. Risk (losses) regressed against risk (gains) and patience & & \\
\hline Variable & Estimate & Std Error & $t$ stat & $P r>|t|$ \\
\hline Intercept & 1.28 & 0.173 & 7.39 & $<.0001$ \\
Risk (gains) & 0.06 & 0.025 & 2.26 & 0.0245 \\
Patience & -0.06 & 0.029 & -2.07 & 0.0388 \\
\hline
\end{tabular}

\section{Discussion}

Our result that psychopathy, Machiavellianism, and nihilism were correlated in the sample is in line with previous literature. Psychopathy and Machiavellianism are distinct traits that have been found to be correlated in the studies of Paulhus and Williams [13]. Bartels and Pizarro [1] also found the two traits to be significantly correlated.

Our findings that risk seekers (when gains were involved) and the risk averse (when losses were involved) were more patient is in line with Frederick [7] and Dohmen et al. [5], who uncover the relation through the mediation of cognitive ability. However, the findings are at odds with works that consider the mediation of impulsivity [12, 14, 15, 11].

Our finding that boys born from younger mothers were more risk seekers (for gains) than girls born from older mothers is also in line with previous work. (See the related findings of Donohue and Levitt [6] and Croson and Gneezy [3].)

Finally, the finding that older participants tended to be less patient is to be viewed with caution - one should bear in mind this result was obtained from a sample of youthful undergraduates.

\section{Conclusion}

Inspired by the result that utilitarians tend to be more psychopathic, Machiavellian and nihilist, we investigated whether risk seekers and the impatient possess such antisocial psychologies. For risk seekers, our study provides an indication that the answer is "yes." This sample of risk seekers tended to be more psychopathic and Machiavellian. Furthermore, because nihilism was correlated with such variables, the study also suggested that risk seekers are antisocial. 
Younger participants in the sample presented, on average, higher levels of psychopathy; atheists were more Machiavellian; and atheists who were anxious tended to be nihilists. Boys born from younger mothers were more risk seeking (for gains) than girls born from older mothers. Older undergraduates tended to be less patient. And finally, those who were both less risk averse for gains and more risk averse to losses tended to be less impatient.

\section{References}

[1] D.M. Bartels and D.A. Pizarro, The mismeasure of morals: Antisocial personality traits predict utilitarian responses to moral dilemmas, Cognition, 121 (2011), 154 - 161.

[2] R. Christie and F.L. Geis, Studies in Machiavellianism, Academic Press, New York, 1970.

[3] R. Croson, R. and U. Gneezy, Gender differences in preferences, Journal of Economic Literature, 47 (2009), 448 - 474.

[4] S. Da Silva, D. Baldo and R. Matsushita, Biological correlates of the Allais paradox, Applied Economics, 45 (2013), 555 - 568.

[5] T. Dohmen, A. Falk, D. Huffman and U. Sunde, Are risk aversion and impatience related to cognitive ability? American Economic Review, 100 (2010), 1238 - 1260.

[6] J. Donohue and S. Levitt, The impact of legalized abortion on crime, NBER Working Paper No. 8004, 2000.

[7] S. Frederick, Cognitive reflection and decision making, Journal of Economic Perspectives, 19 (2005), 25 - 42.

[8] R.M. Kowalski (Ed.), Behaving Badly: Aversive Behaviors in Interpersonal Relationships, American Psychological Association, Washington, 2001. 
[9] R.G. Kunzendorf, C. Moran and R. Gray, Personality traits and reality-testing abilities, controlling for vividness of imagery, Imagination, Cognition and Personality, 15 (1995), 113 - 131.

[10] M.R. Levenson, K.A. Kiehl and C.M. Fitzpatrick, Assessing psychopathic attributes in a noninstitutional population, Journal of Personality and Social Psychology, 68 (1995), 151 - 158.

[11] I.P. Levin and S.S. Hart, Risk preferences in young children: Early evidence of individual differences in reaction to potential gains and losses, Journal of Behavioral Decision Making, 16 (2003), 397 - 413.

[12]W. Mischel, Y. Shoda and M.L. Rodriguez, Delay of gratification in children, Science, 244 (1989), 933 - 938.

[13]D.L. Paulhus and K.M. Williams, The dark triad of personality: Narcissism, Machiavellianism, and psychopathy, Journal of Research in Personality, 36 (2002), $556-563$.

[14]B. Reynolds, A. Ortengren, J.B. and H. de Wit, Dimensions of impulsive behavior: Personality and behavioral measures, Personality and Individual Differences, 40 (2006), 305 - 315.

[15]R.E. Vuchinich and M.L. Calamas, Does the repeated gambles procedure measure impulsivity in social drinkers? Experimental and Clinical Psychopharmacology, 5 (1997), 157 - 162.

\section{Received: August 16, 2014}

